\title{
E-GOVERNMENT IN RUSSIA: THE PROBLEM OF DETERMINING THE PERFORMANCE CRITERIA AND ACHIEVEMENT INDICATORS
}

\author{
Evgeniy A. Mamay \\ Nizhny Novgorod Academy of the Ministry of Interior of Russia, Nizhny Novgorod, Russian Federation
}

Introduction: the development of the state and municipal administration in Russia is in the direction of digitalization. The provision of public (state and municipal) services is converted into electronic form, which has a number of advantages and limitations compared to the traditional forms of their implementation. Without the establishment of clear goals, it is impossible to adequately assess the prospects for the development of this institution and further regulations.

The purpose of the research is to determine the criteria for the development of e-government and the establishment of the public policy objective indicators in this area.

The research methodology is based on the application of the logical, dialectical techniques and the methods of scientific knowledge, and the comparative law and legal-technical analysis of the texts of laws and other documents.

Results: in the article the author conducts the analysis of the foreign scientific literature, the international ratings of the Russian legislation and the strategic planning documents for the establishment of the criteria for determining the stages of forming the electronic government in Russia, and the efficiency of the state policy in the regulation sphere. The study of the issue suggests the absence of a strategic vision of the prospects for the development of e-government, the imperfection of the state programs implementation indicators, the use as the planned results of the reforms of preliminary indicators obtained without the appropriate justification, the assumption of the possibility of information manipulation and inefficient spending of budgetary resources.

Conclusions: in modern Russia there is no holistic vision of the prospects for digitalization of the public administration. Due to the lack of the theoretical study of the issues of understanding of "serviceability" in the public administration, the classification of the state and municipal services procedures that have control and supervisory nature, the limits of the relevant sphere regulation are not clearly determined. The strategic planning documents and the federal legislation are often adopted in a haphazard manner, and the targets achievement is subject to the manipulation without a factual basis. According to the author of the article, the solution of these problems is seen in determining the essence of public, state and municipal services, the establishment of a clear system of the statutory and law enforcement regulation.

Key words: e-government services, public services, service state, state and municipal services, e-government, federal state.

Citation. Mamay E. A. E-Government in Russia: the Problem of Determining the Performance Criteria and Achievement Indicators. Legal Concept, 2018, vol. 17, no. 4, pp. 35-44. DOI: https://doi.org/10.15688/lc.jvolsu.2018.4.5

УДК $34.07 ; 351 / 354 ; 342.951$

ББК 67.401

Дата поступления статьи: 03.10.2018

Дата принятия статьи: 22.10.2018

\section{ЭЛЕКТРОННОЕ ПРАВИТЕЛЬСТВО В РОССИИ: ПРОБЛЕМА ОПРЕДЕЛЕНИЯ КРИТЕРИЕВ ЭФФЕКТИВНОСТИ И ДОСТИЖЕНИЯ ПОКАЗАТЕЛЕЙ}

\author{
Евгений Алексеевич Мамай \\ Нижегородская академия МВД России, г. Нижний Новгород, Российская Федерация
}

Введение: развитие государственного и муниципального управления в России идет в направлении цифровизации. Оказание публичных (государственных и муниципальных) услуг переводится в электронную форму, имеющую ряд преимуществ и ограничений по сравнению с традиционными формами их воплоще- 
ния. Без установления четких целей невозможна адекватная оценка перспектив развития данного института и дальнейшего нормативного правового регулирования.

Целью публикации является определение критериев развития электронного правительства и установление объективных показателей государственной политики в рассматриваемой сфере.

Методология исследования базируется на применении логического, диалектического приемов и способов научного познания, сравнительно-правового и юридико-технического анализа текстов законов и иных документов.

Результаты: в статье проводится анализ зарубежной научной литературы, международных рейтингов, российского законодательства и документов стратегического планирования на предмет установления критериев, позволяющих определить этапы становления электронного правительства в России, эффективности государственной политики в рассматриваемой сфере регулирования. Проведенное исследование вопроса позволяет говорить об отсутствии стратегического видения перспектив развития электронного государства, несовершенстве показателей реализации государственных программ, использовании в качестве планируемых результатов реформ предварительных показателей, полученных без соответствующих обоснований, допущение возможностей манипулирования сведениями и неэффективного расходования бюджетных ресурсов.

Выводы: в современной России отсутствует целостное видение перспектив цифровизации государственного управления. Ввиду недостаточной теоретической проработки вопросов понимания «сервисности» в госуправлении, отнесения к разряду государственных и муниципальных услуг процедур, имеющих контрольно-надзорный характер, пределы регулирования соответствующей сферы четко не определены. Документы стратегического планирования и федеральное законодательство зачастую принимаются бессистемно, а достижение плановых показателей подвергается манипуляциям, не имеющим под собой фактической основы. По мнению автора публикации, решение этих проблем видится в определении сущности публичных, государственных и муниципальных услуг, установлении четкой системы нормативного и правореализационного регулирования.

Ключевые слова: электронные госуслуги, публичные услуги, сервисное государство, государственные и муниципальные услуги, электронное правительство, федеративное государство.

Цитирование. Мамай Е. А. Электронное правительство в России: проблема определения критериев эффективности и достижения показателей // Legal Concept = Правовая парадигма. - 2018. - T. 17, № 4. C. 35-44. - DOI: https: //doi.org/10.15688/lc.jvolsu.2018.4.5

\section{Введение}

Рост интереса государств мира к построению информационного общества и перспективам развития электронного государства начался в конце 1980-х - начале 1990-х годов. В это время в отдельных странах Европы началось создание рабочих групп, занимающихся установлением общих принципов и выработкой стандартов урегулирования соответствующих вопросов.

К началу 2000-х гг. отдельные государства подошли к стадии практического воплощения принципов электронного государства: началось внедрение электронных идентификаторов личности, подписание соответствующих соглашений между органами управления на общегосударственном, региональном и муниципальном уровне, создавались сети телекоммуникации. В это же время стали формулироваться базовые критерии цифровизации государственного управления. Так, в 2001 г. Орга- низацией объединенных наций были разработаны исходные критерии для составления рейтинга стран - членов ООН в обеспечении равного доступа к государственному управлению и получению публичных услуг гражданами посредством внедрения информационно-телекоммуникационных технологий (ИКТ) в деятельность публичных администраций [19].

С течением лет, по мере проведения преобразований в сфере государственного управления, рейтинги России в различных общемировых рейтингах остаются стабильными или постепенно повышаются. Так, ООН в своем рейтинге развития электронного правительства в 2012, 2014 гг. ставила Россию на 27-е место, в 2016 г. наша страна занимала 35-е, в 2018 г. 32-е место. По рейтингу развития информационного общества, ежегодно составляемому Международным телекоммуникационным союзом (International Telecommunication Union, ITU), в 2007 г. Россия находилась на 50-м месте в списке из 154 государств, а в 2017 г. зани- 
E.A. Мамай. Электронное правительство в России: проблема определения критериев эффективности

мала 45-е место в списке из 176 стран мира [23]. Рейтинг «Doing Business» в 2013 году помещал Россию на 112-е место в списке из 185 стан, а в 2018 г. - уже на 35-е (из 190 стран, охваченных рейтингом) [21].

Опыт зарубежных государств и ежедневная практика администрирования в самой Российской Федерации показывают значительную инертность становления системы электронного государства на различных уровнях государственного и муниципального управления. Мировой опыт свидетельствует о стратегическом преимуществе небольших экономически развитых государств в развитии сферы функционирования электронного государства и обеспечении равного доступа граждан к результатам его деятельности.

В указанном контексте представляется интересным и научно обоснованным разобраться в критериях становления электронного государства, эффективности реализации электронных госуслуг и объективной возможности достижения плановых показателей в условиях современного российского государства.

\section{Основное содержание}

В научной литературе, посвященной теоретическим проблемам цифровизации государственного управления, достаточно давно оформилось и нашло подтверждение во множестве фактов мнение, что развитие электронного государства является эволюционным процессом. Д. Тэпскотт, А. Лови, Д. Тиколь, Н. Клим еще в 1998 г. обозначали схожесть эволюционного развития электронного государства и электронной коммерции. Государство, также как и бизнес, следует по пути развития от наиболее простой стадии трансляции через последующие стадии взаимодействия и транзакций - к интеграционной стадии [20]. К. Вагнер, К. Ченг, Ф. Ли, Р. Ип следующим образом раскрывают названные этапы развития электронного государства [22, p. 13]. На стадии трансляции электронное государство ограничивается простым присутствием в сети Интернет, страницы имеют статичный характер и просто обеспечивают получение информации. На интерактивной стадии сайты органов госуправления позволяют обмениваться информацией с гражданами, а сами потребители могут получать некоторые ресурсы из информационных баз, расположенных на соответствующих порталах. На транзакционной стадии гражданам становится доступной возможность совершения финансовых операций через сайты органов власти (например, уплата штрафов, налогов, госпошлин и т. п.). Данный этап подразумевает высокий уровень обработки информации, надежность и безопасность платежных терминалов. Наконец, электронное правительство достигает интеграционной стадии, когда все субъекты администрирования в государстве эффективно взаимодействуют, исключается дублирование функций, а реализация, как правило, происходит через единый портал доступа ко всем сервисам государства.

Отметим, что в упомянутом выше рейтинге стран-участниц ОНН ключевые критериальные позиции базируются как раз на оценке стадий развития электронного государства: официальное присутствие органов власти в сети Интернет; тип предоставления услуг через сайты: базовое или информационное обеспечение, интерактивное взаимодействие (стадия обмена информацией) и транзакционное взаимодействие (возможность проведения через официальные сайты оплат и иных операций); реализация сервисов в пяти критически важных областях (образование, здравоохранение; занятость населения; социальные и финансовые услуги); использование единых точек доступа (порталов госуслуг); следование стратегическим планам развития электронного государства [19].

Несмотря на то, что перечисленные критерии во многом имеют оценочный характер, результаты самого рейтинга достаточно показательны. Согласно данному исследованию, в 2001 г. из 190 государств-членов имели сайты правительственных учреждений только 169 стран, из них около половины (84 государства) не имели никаких правительственных сайтов, кроме сайтов центральных органов государственного управления, только 36 имели единые информационные порталы, а возможность осуществления финансовых операций через них предоставляли сайты только в 17 странах. Потенциал России рейтинг $\mathrm{OOH}$ оценивал как средний с показателем 1,92 балла при среднем общемировом показателе рав- 
ном 1,62 балла, лидирующем - 3,11, замыкающем - 0,46 балла. С начала 2000-х гг. по настоящее время места в десятке государствлидеров практически постоянно занимают Австралия и Новая Зеландия, однако в числе передовых государств, получающих наибольшие коэффициенты развития электронного государства, из года в год превалируют Дания, Южная Корея, Соединенное Королевство Великобритании и Северной Ирландии, Швеция, Финляндия, Сингапур, Франция, Япония, Нидерланды, Норвегия.

В России, как это и следует из ее федеративного статуса, именно органы государственной власти федерального уровня власти берут на себя полномочия координаторов производимых реформ, в том числе в сфере осуществления публичных услуг. Инициирование подобных изменений именно «сверху», с верхнего уровня госуправления, является общепринятой практикой. Так, например, в Австрии федеральное правительство, реализуя планы цифровизации государства, еще в 1998 г. подписало соответствующие соглашения о кооперации в ИТ-сфере с отдельными землями, входящими в состав федерации (IT-Cooperation Agreement, Die Kooperationvon Bundund Landern), а начиная с 2003 г. инициировало реализацию планов по внедрению принципов электронного правительства.

В России программные документы, касающиеся административной реформы, также стали озвучиваться около двух десятилетий назад. Так, еще в 1998 г. в своем послании Федеральному Собранию России Президент России Б.Н. Ельцин отмечал: «Подъем в России невозможно обеспечить без эффективной власти, работающей на принципах служения обществу, а не самой себе (выделено нами. E. M.)» [5]. Говоря о необходимости административной реформы, еще тогда президент наметил разграничение функиий собственно управления и функций оказания государственных услуг. Тогда же был принят Указ Президента России «О мерах по устранению административных барьеров при развитии предпринимательства» [12], который на федеральном уровне реализован не был, а в региональном контексте выразился в создании межведомственных комиссий по изучению административных барьеров для бизнеса [1].
Логику рассуждений Б.Н. Ельцина в дальнейшем продолжил и В.В. Путин. Еще в 2004 г. он намечал цель осуществления административной реформы: «...каждый гражданин будет не только знать, но и будет иметь возможность реально требовать тот уровень и то качество услуг, которые ему обязаны предоставить конкретные уровни власти. И, разумеется, он будет непосредственно влиять на принятие решений, которые его касаются» [2].

Намерения, высказанные в программных документах начала 2000-х гг., стали получать свое реальное воплощение вместе с реализацией прочих мероприятий в рамках масштабной административной реформы. В 2004 г. были предприняты попытки осуществить ревизию функций и направлений деятельности, реализуемых органами государственной и муниципальной власти. Так, в рамках административной реформы был проведен анализ и классификация функций, осуществляемых федеральными органами исполнительной власти. Всего было проанализировано 5634 функции, из них были признаны избыточными 1 468, дублирующими друг друга - 263, требующими изменения - 868 [7]. Тем не менее потенциально необходимый результат - в виде соответствующего реестра государственных и муниципальных услуг/функций - до сих пор не получен.

В 2008 г. Президентом России была утверждена Стратегия развития информационного общества в Российской Федерации (далее - Стратегия-2008), одной из целей реализации которой было определено «повышение эффективности государственного управления и местного самоуправления, взаимодействия гражданского общества и бизнеса с органами государственной власти, качества и оперативности предоставления государственных услуг» [10].

Контрольные значения показателей развития информационного общества в Российской Федерации на период до 2015 г., установленные Стратегией-2008, большей частью реализованы не были. Так, ни в одном из международных рейтингов, ни по развитию информационного общества, ни по доступности инфраструктуры, Россия никогда не занимала места выше третьего десятка. Федеральным органам власти не удалось решить проблем 
E.A. Мамай. Электронное правительство в России: проблема определения критериев эффективности

со значительными различиями в уровне развития цифровых технологий в различных регионах России. Необоснованными показателями в дальнейшем пришлось признать 100 \%-ю долю государственных услуг, доступных для получения в электронной форме, а также 70 \%-й объем электронного документооборота между органами госвласти. Наибольшими достижениями, реализованными в рамках Стратегии-2008, можно признать внедрение электронных процедур в сферу госзакупок $[15 ; 16]$, которая, однако, с тех пор продолжает оставаться предметом для споров, а также принятие федерального закона «Об организации предоставления государственных и муниципальных услуг» [14].

В общем ключе проводимых преобразований на сайте административной реформы с ноября 2011 г. стала регулярно публиковаться информация об актуализации перечня государственных функций и услуг, объем которого с каждым годом продолжает прогрессировать. Так, по состоянию на 29 сентября 2018 г. актуализированный перечень, размещенный на сайте административной реформы, включает в себя 878 наименований [4]. Обращает на себя внимание тот факт, что ежемесячно указанный перечень дополняется в среднем десятью новыми позициями, из которых «услуги», связанные с контролем (надзором), составляют практически четверть (в настоящее время таковых свыше 200). Относимость контрольно-надзорных полномочий органов власти и управления к сфере публичных услуг до сих пор составляет предмет для сомнения.

Стратегия-2008 утратила свою силу в связи с принятием в мае 2017 г. новой Стратегии развития информационного общества в Российской Федерации на 2017-2030 гг. (далее - Стратегия-2017) [11]. Обращает на себя внимание, что одним из основных принципов вновь принятого документа было определено «сохранение традиционных и привычных для граждан (отличных от цифровых) форм получения товаров и услуг», подчеркнута тем самым необходимость оказания публичных услуг в традиционной («бумажной») форме, привычной для значительной части населения страны. Данная мысль прослеживается сквозь весь рассматриваемый документ. К примеру, в социальной сфере, системе го- сударственного управления Статегия-2017 предписывает сохранять возможности взаимодействия граждан с организациями и органами управления без применения информационных технологий.

Критериальные позиции, определяемые Стратегией-2017, дают некоторые основания для разночтений. Так, по данным международного телекоммуникационного союза (ITU), российская аудитория сети Интернет в 2017 г. составила 62 млн человек [24], в то время как сама Стратегия-2017 пользователями российского сегмента сети Интернет называла более 80 млн человек уже по состоянию на конец 2016 года.

В контексте Статегии-2017 и общей численности пользователей сети Интернет, объявленной данным документом, следует рассматривать и показатели, касающиеся эффективности работы центрального информационного ресурса электронного правительства - Единого портала государственных и муниципальных услуг (ЕПГУ). Примечательно, что уже в Концепции развития механизмов предоставления государственных и муниципальных услуг в электронном виде, утвержденной Распоряжением Правительства РФ от 25 декабря 2013 года № 2516-р, отмечалась низкая эффективность функционирования данного ресурса. Так, по состоянию на 2013 г. возможность получения результата предоставления услуги была реализована лишь для 3,3 \% услуг, предоставляемых на федеральном уровне, а среди услуг, предоставляемых на региональном и муниципальном уровнях, таковая была возможна только для $1,1 \%$ услуг [6]. Таким образом, выявленная динамика изначально исключала возможность достижения плановых показателей (в частности повышения к 2018 г. до 70 \% доли граждан, использующих механизм получения услуг в электронном виде), установленных одним из майских указов Президента России В.В. Путина [13].

Сама Стратегия-2017 также содержит сведения, противоречащие официальной статистике Минкомсвязи. В ней, в частности, декларировалось создание системы предоставления государственных и муниципальных услуг в электронной форме, к которой подключились более 34 млн россиян [11]. Официаль- 
ная же отчетность Министерства связи и массовых коммуникаций Российской Федерации уже на конец 2016 г. объявляла достижение показателя 40 млн человек, зарегистрированных на Едином портале госуслуг, что, в числе прочего, не в полной мере состыковывается с общей численностью пользователей сети Интернет в России. Достаточно спорны и показатели ежегодного прироста: по официальной статистике, в 2015 г. общее число пользователей было 22,5 млн человек, в 2014 г. 13 млн, в 2013 г. - 6,9 млн человек [3].

Кроме того, развитие электронного государства в России, по мнению разработчиков реформы, должно было привести к планомерному сокращению различий по интегральным и прочим показателям между субъектами Российской Федерации. В рассматриваемом контексте обращают на себя внимание итоги ежегодного опроса, проведенного Росстатом по показателю «Доля граждан, использующих механизм получения государственных и муниципальных услуг в электронной форме». Респодентам, участвовавшим в 2017 г. в данном исследовании, задавался вопрос о получении ими в течение последних 12 месяцев государственных и муниципальных услуг и способе их получения. У лидеров рейтинга (Московской области, Ямало-Ненецкого автономного округа) доля граждан, получивших госуслуги через Интернет, составила $86 \%$, в Татарстане - $80 \%$. Самые же низкие показатели продемонстрировал опрос граждан в Костромской области (37\%), Еврейской автономной области $(36 \%)$ и Чукотском автономном округе (19\%) [9].

Благостная картина, демонстрируемая статистикой Росстата, омрачается двумя факторами, говорящими, на наш взгляд, о «рукотворном» характере статистики, поступающей из большинства регионов России. Во-первых, это резкий прирост, продемонстрированный в 2017 г. такими регионами, как Республика Тыва (плюс 49 процентных пункта за год), Красноярский край (плюс 48 \%), Ямало-Ненецкий автономный округ (плюс $46 \%$ ), Московская область и Карачаево-Черкесская Республика (по 42 процентных пункта каждый). Во-вторых, это резкий контраст между регионами, демонстрирующими самые высокие показатели, и городами федерального значе- ния, которые традиционно опережают средние показатели по России по использованию цифровых технологий. К примеру, Росстат декларирует, что на 1 марта 2018 г. 17 субъектов Российской Федерации преодолели отметку в $70 \%$ по доле граждан старше 14 лет, зарегистрированных в Единой системе идентификации и аутентификации (ЕСИА). По необъяснимым, с нашей точки зрения, причинам лидеры рейтинга - Ненецкий автономный округ (95,2 \%), Республика Тыва (93,5 \%), Чукотский автономный округ (87,6 \%), Ханты-Мансийский автономный округ (85,2 \%) и ЯмалоНенецкий автономный округ $(81,0 \%)$ - значительно опережают Санкт-Петербург $(49,2 \%)$ и Москву (45,2 \%) [8].

Косвенным подтверждением высказываемых нами сомнений являются результаты исследования «Цифровая жизнь российских мегаполисов», которое еще в 2016 г. выявляло определенные диспропорции в проникновении цифровых технологий в жизнь регионов России: если в Москве Интернетом регулярно пользовались более $90 \%$ населения, то в Перми или Волгограде - чуть более 70 \% [18]. В этом же контексте трудно объяснить, почему, например, Чукотский автономный округ фигурирует в числе лидеров по количеству граждан, зарегистрированных в ЕСИА, но демонстрирует самый низкий показатель по количеству граждан, получивших электронные госуслуги.

\section{Заключение}

Электронное государство в целом, как и частное его проявление, сфера реализации государственных и муниципальных услуг в электронном виде, по общему правилу, исключает конкуренцию государства с иными участниками общественных отношений (и поставщиками услуг). Устранение государства из указанной сферы может повлечь за собой масштабные негативные последствия, однако и излишняя зарегулированность указанной сферы также обладает пролонгированным негативным эффектом. Проведенный нами анализ показывает, что в условиях федеративного государства именно на федеральный уровень государственного управления возлагается особая ответственность за планомерность 
E.A. Мамай. Электронное правительство в России: проблема определения критериев эффективности

проведения преобразований. Передача регулятивных полномочий на нижележащие уровни управления (например, в форме создания саморегулирующих организаций в определенных сферах профессиональной деятельности, передача полномочий от федерального уровня власти на региональный и местный) имеет как свои позитивные последствия, так и негативный фон, выражающийся в разрозненности государственной политики и манипулировании сведениями в ущерб достижению реальных показателей. Согласно исследованию «Цифровизация в малых и средних городах России», наиболее значимые различия наблюдаются в использовании онлайн-услуг, касающихся взаимодействия именно с местными учреждениями (записи на прием к врачу и решения вопросов в сфере ЖКХ), в отличие от оплаты штрафов, налогов, оформления документов и других услуг, стандартизированных на федеральном уровне и не имеющих локальной привязки к региону или городу [17].

Государство в лице федерального правительства не должно полностью слагать с себя регулятивные полномочия, осуществляя координирующую функцию, активно контролируя реализацию правомочий и обеспечивая исполнение обязанностей, сопровождая наделение ими соответствующим финансированием.

\section{СПИСОК ЛИТЕРАТУРЫ}

1. Административные барьеры: опыт преодоления субъектами Российской Федерации : Исследование. - М. : Ресурсный центр малого предпринимательства, 2001. - 130 с.

2. Выступление Владимира Путина перед доверенными лицами. - Электрон. дан. - 12 февраля 2004 г. - Режим доступа: http://www.kremlin.ru/ transcripts/22393 (дата обращения: 21.10.2018). Загл. с экрана.

3. На Едином портале госуслуг зарегистрирован каждый второй пользователь Рунета / Министерство цифрового развития, связи и массовых коммуникаций Российской Федерации. - Электрон. дан. Режим доступа: https://minsvyaz.ru/ru/events/36373/ (дата обращения: 21.10.2018). - Загл. с экрана.

4. Перечень государственных услуг и функций на 29.09.2018 // AR.GOV.RU. Совершенствование государственного управления. Документы. Электрон. дан. - Режим доступа: http://ar.gov.ru/ru-
RU/document/default/view/522 (дата обращения: 20.10.2018). - Загл. с экрана.

5. Послание Президента РФ Федеральному Собранию от 17 февраля 1998 года «Общими силами - к подъему России : (о положении в стране и основных направлениях политики Российской Федерации)» // Российская газета. - 1998. - 24 февр. (№36).

6. Постановление Правительства РФ от 15 апреля 2014 № 313 (ред. от 25.09.2018) «Об утверждении государственной программы Российской Федерации "Информационное общество (20112020 годы)"» // Собрание законодательства РФ. 2014. - 5 мая (№ 18 (часть II)). - Ст. 2159.

7. Распоряжение Правительства РФ от 25 октября 2005 г. № 1789-р (ред. от 10.03.2009) «О Концепции административной реформы в Российской Федерации в 2006-2010 годах» // Собрание законодательства Рос. Федерации. - 2005. - № 46. Ст. 4720.

8. Рейтинг регионов по доле граждан, зарегистрированных в ЕСИА на 1 марта 2018 года. - Электрон. дан. - Режим доступа: http://d-russia.ru/ kolichestvo-regionov-preodolevshih-70-protsentnuyuotmetku-po-dole-grazhdan-zaregistrirovannyh-v-esiadostiglo-17.html (дата обращения: 21.10.2018). - Загл. с экрана.

9. Росстат посчитал долю граждан, получавших электронные госуслуги в 2017 году. - Электрон. дан. - Режим доступа: http://d-russia.ru/rosstatposchital-dolyu-grazhdan-poluchavshih-elektronnyegosuslugi-v-2017-godu.html (дата обращения: 21.10.2018). - Загл. с экрана.

10. Стратегия развития информационного общества в Российской Федерации : утв. Президентом РФ 7 февраля 2008 г. № Пр-212 // Российская газета. - 2008. -16 февр. (№ 34).

11. Стратегия развития информационного общества в Российской Федерации на 2017-2030 гг. : утв. Указом Президента РФ от 9 мая 2017 г. № 203 // Собрание законодательства РФ. - 2017. - 15 мая (№ 20). - Ст. 2901.

12. Указ Президента Российской Федерации № 730 от 29 июня 1998 года «О мерах по устранению административных барьеров при развитии предпринимательства» // Российская газета. 1998. - 1 июля (№ 122).

13. Указ Президента Российской Федерации от 7 мая 2012 г. № 601 «Об основных направлениях совершенствования системы государственного управления» // Российская газета. - 2012. 9 мая.

14. Федеральный закон от 27 июля 2010 г. № 210-Ф3 «Об организации предоставления государственных и муниципальных услуг» // Российская газета. $-2010 .-30$ июля (№ 168). 
15. Федеральный закон от 18 июля 2011 г. № 223-Ф3 «О закупках товаров, работ, услуг отдельными видами юридических лиц» // Российская газета. - 2011. - 22 июля (№ 159).

16. Федеральный закон от 5 апреля 2013 г. № 44Ф3 «О контрактной системе в сфере закупок товаров, работ, услуг для обеспечения государственных и муниципальных нужд» // Российская газета. 2013. - 12 апр. (№ 80).

17. Цифровизация в малых и средних городах России - исследование. - Электрон. дан. - Режим доступа: http://d-russia.ru/tsifrovizatsiya-v-malyh-isrednih-gorodah-rossii-issledovanie.html (дата обращения: 15.10.2018). - Загл. с экрана.

18. Цифровая жизнь российских мегаполисов : Модель. Динамика. Примеры / Институт исследований развивающихся рынков бизнес-школы СКОЛKOBO (IEMS). - Электрон. дан. - 2016. - Режим доступа: https://iems.skolkovo.ru/downloads/ documents/SKOLKOVO_IEMS/Research_Reports/ SKOLKOVO_IEMS_Research_2016-11-30_ru.pdf (дата обращения: 15.10.2018). - Загл. с экрана.

19. Benchmarking E-government: A Global Perspective. Assessing the Progress of the UN Member States. - Electronic text data. - Mode of access: https:/ /publicadministration.un.org/egovkb/Portals/egovkb/ Documents/un/English.pdf (date of access: 12.10.2018). - Title from screen.

20. Blueprint to the digital economy: creating wealth in the era of e-business / D. Tapscott, A. Lowy, D. Ticoll, N. Klym. - N. Y. : McGraw-Hill, 1998.-410p.

21. Doing Business 2018 : Reforming to Create Jobs. - Electronic data. - The World Bank, 2018. Mode of access: http://www.doingbusiness.org/ content/dam/doingBusiness/media/Annual-Reports/ English/DB2018-Full-Report.pdf (date of access: 12.10.2018). - Title from screen.

22. Enhancing E-government in Developing Countries: Managing Knowledge through Virtual Communities / C. Wagner, K. Cheung, F. Lee, R. Ip // Wiley Online Library. EJISDC (The Electronic Journal on Information Systems in Developing Countries). 2003. - Vol. 14, iss. 1. - Mode of access: https:// onlinelibrary.wiley.com/doi/10.1002/j.16814835.2003.tb00095.x (date of access: 12.10.2018). - Title from screen.

23. ICT Development Index // ITU (International Telecommunication Union). - Electronic data. - Mode of access: https://www.itu.int/net4/ITU-D/idi/2017/ (date of access: 12.10.2018). - Title from screen.

24. New data visualization on Internet users by region and country, 2010-2016 // ITU (International Telecommunication Union). - Electronic data. - Mode of access: https:/www.itu.int/en/ITU-D/Statistics/ Pages/stat/default.aspx (date of access: 12.10.2018). Title from screen.

\section{REFERENCES}

1. Administrativnye baryery: opyt preodoleniya subyektami Rossiyskoy Federatsii: Issledovanie [Administrative Barriers: The Experience of Overcoming by the Entities of the Russian Federation: Research]. Moscow, Resursnyy tsentr malogo predprinimatelstva Publ., 2001. 130 p.

2. Vystuplenie Vladimira Putina pered doverennymi litsami (12 fevralya 2004 g.) [Speech by Vladimir Putin to Proxies (12 February 2004)]. URL: http://www.kremlin.ru/transcripts/22393 (accessed 21 October 2018).

3. Na Edinom portale gosuslug zaregistrirovan kazhdyy vtoroy polzovatel Runeta / Ministerstvo tsifrovogo razvitiya, svyazi i massovykh kommunikatsiy Rossiyskoy Federatsii [Every Second User of the Runet Is Registered on the Unified Portal of Public Services / Ministry of Digital Development, Communications and Mass Communications of the Russian Federation]. URL: https://minsvyaz.ru/ru/ events/36373/ (accessed 21 October 2018).

4. Perechen gosudarstvennykh uslug i funktsiy na 29.09.2018 [The List of Public Services and Functions for 29 September 2018]. AR.GOV.RU. Sovershenstvovanie gosudarstvennogo upravleniya. Dokumenty [AR.GOV.RU. Improving Public Administration. Documents]. URL: http://ar.gov.ru/ru-RU/document/ default/view/522 (accessed 20 October 2018).

5. Poslanie Prezidenta RF Federalnomu Sobraniyu ot 17 fevralya 1998 goda «Obshchimi silami - k podyemu Rossii: (o polozhenii v strane i osnovnykh napravleniyakh politiki Rossiyskoy Federatsii)» [The Message of the President of the Russian Federation to the Federal Assembly of 17 February 1998 "By Common Forces - to the Rise of Russia: (on the Situation in the Country and the Main Areas of the Policy of the Russian Federation)"]. Rossiyskaya gazeta, 1998, 24 February (no. 36).

6. Postanovlenie Pravitelstva RF ot 15 aprelya 2014 № 313 (red. ot 25.09.2018) «Ob utverzhdenii gosudarstvennoy programmy Rossiyskoy Federatsii "Informatsionnoe obshchestvo (2011-2020 gody)"》" [Resolution of the Government of the Russian Federation of 15 April 2014 No. 313 (amend. of 25 September 2017) 'On Approval of the State Program of the Russian Federation "Information Society (20112020)"']. Sobranie zakonodatelstva RF [Collected Legislation of the Russian Federation], 2014, 5 May (no. 18 (Part II)), art. 2159.

7. Rasporyazhenie Pravitelstva RF ot 25 oktyabrya 2005 g. № 1789-r (red. ot 10.03.2009) «O Kontseptsii administrativnoy reformy v Rossiyskoy Federatsii v 2006-2010 godakh» [Order of the Government of the Russian Federation of 25 October 2005 No. 1789-p (amend. of 10 March 2009) 
"On the Conception of Administrative Reform in the Russian Federation in 2006-2010"]. Sobranie zakonodatelstva RF [Collected Legislation of the Russian Federation], 2005, no. 46, art. 4720.

8. Reyting regionov po dole grazhdan, zaregistrirovannykh v ESIA na 1 marta 2018 goda [Rating of Regions by the Share of Citizens Registered in the ESIA as of 1 March 2018]. URL: http://d-russia.ru/ kolichestvo-regionov-preodolevshih-70-protsentnuyu -otmetku-po-dole-grazhdan-zaregistrirovannyh-vesia-dostiglo-17.html (accessed 21 October 2018).

9. Rosstat poschital dolyu grazhdan, poluchavshikh elektronnye gosuslugi $v 2017$ godu [Rosstat Counted the Share of Citizens Who Received E-Government Services in 2017]. URL: http://d-russia.ru/ rosstat-poschital-dolyu-grazhdan-poluchavshihelektronnye-gosuslugi-v-2017-godu.html (accessed 21 October 2018).

10. Strategiya razvitiya informatsionnogo obshchestva v Rossiyskoy Federatsii: utv. Prezidentom RF 7 fevralya 2008 g. № Pr-212 [The Strategy of Information Society Development in the Russian Federation: Approved by the President of the Russian Federation on 7 February 2008 No. Pr-212]. Rossiyskaya gazeta, 2008, 16 February (no. 34).

11. Strategiya razvitiya informatsionnogo obshchestva v Rossiyskoy Federatsii na 2017-2030 gg.: utv. Ukazom Prezidenta RF ot 9 maya 2017 g. № 203 [Strategy of Information Society Development in the Russian Federation for 2017-2030: Approved by Decree of the President of the Russian Federation of 9 May 2017 No. 203]. Sobranie zakonodatelstva RF [Collected Legislation of the Russian Federation], 2017, 15 May (no. 20), art. 2901.

12. Ukaz Prezidenta Rossiyskoy Federatsii № 730 ot 29 iyunya 1998 goda «O merakh po ustraneniyu administrativnykh baryerov pri razvitii predprinimatelstva» [Decree of the President of the Russian Federation No. 730 of 29 June 1998 'On Measures for Eliminating Administrative Barriers in the Development of Entrepreneurship']. Rossiyskaya gazeta, 1998, 1 July (no. 122).

13. Ukaz Prezidenta Rossiyskoy Federatsii ot 7 maya 2012 g. № 601 «Ob osnovnykh napravleniyakh sovershenstvovaniya sistemy gosudarstvennogo upravleniya» [Decree of the President of the Russian Federation of 7 May 2012 No. 601 'On the Main Directions of Improvement of the Public Administration System"]. Rossiyskaya gazeta, 2012, 9 May.

14. Federalnyy zakon ot 27 iyulya $2010 \mathrm{~g}$. № 210 -FZ «Ob organizatsii predostavleniya gosudarstvennykh i munitsipalnykh uslug» [Federal Law of 27 July 2010 No. 210-FZ 'On Provision of State and Municipal Services']. Rossiyskaya gazeta, 2010, 30 July (no. 168).
15. Federalnyy zakon ot 18 iyulya 2011 g. № 223$\mathrm{FZ}$ «O zakupkakh tovarov, rabot, uslug otdelnymi vidami yuridicheskikh lits» [Federal Law of 18 July 2011 No. 223-FZ 'On the Procurement of Goods, Works,Services by Certain Types of Legal Entities']. Rossiyskaya gazeta, 2011, 22 July (no. 159).

16. Federalnyy zakon ot 5 aprelya 2013 g. № 44-FZ «O kontraktnoy sisteme v sfere zakupok tovarov, rabot, uslug dlya obespecheniya gosudarstvennykh i munitsipalnykh nuzhd» [Federal Law of 5 April 2013 No. 44-FZ 'On the Contract System in the Field of Procurement of Goods, Works, Services for State and Municipal Needs"]. Rossiyskaya gazeta, 2013, 12 April (no. 80).

17. Tsifrovizatsiya $v$ malykh i srednikh gorodakh Rossii: issledovanie [Digitalization in Small and Medium-Sized Cities of Russia. Research]. URL: http:// d-russia.ru/tsifrovizatsiya-v-malyh-i-srednih-gorodahrossii-issledovanie.html (accessed 15 October 2018).

18. Tsifrovaya zhizn rossiyskikh megapolisov: Model. Dinamika. Primery / Institut issledovaniy razvivayushchikhsya rynkov biznes-shkoly SKOLKOVO (IEMS) [The Digital Life of Russian Megalopolises: Model. Dynamics. Examples / Institute for Emerging Market Research, SKOLKOVO Business School]. URL: https://iems.skolkovo.ru/downloads/ documents/SKOLKOVO IEMS/Research Reports/ SKOLKOVO_IEMS_Research_2016-11-30_ru.pdf (accessed 15 October 2018).

19. Benchmarking E-government: A Global Perspective. Assessing the Progress of the UNMember States. URL: https://publicadministration.un.org/ egovkb/Portals/egovkb/Documents/un/English.pdf (accessed 12 October 2018).

20. Tapscott D., LowyA., Ticoll D., Klym N. Blueprint to the digital economy: creating wealth in the era of e-business. New York, McGraw-Hill, 1998.410p.

21. Doing Business 2018 : Reforming to Create Jobs. The World Bank, 2018. URL: http:// www.doingbusiness.org/content/dam/doingBusiness/ media/Annual-Reports/English/DB2018-FullReport.pdf (accessed 12 October 2018).

22. Wagner C., Cheung K., Lee F., Ip R. Enhancing E-government in Developing Countries: Managing Knowledge through Virtual Communities. The Electronic Journal on Information Systems in Developing Countries, 2003, vol. 14, iss. 1. URL: https:/ /onlinelibrary.wiley.com/doi/10.1002/j.1681 4835.2003.tb00095.x (accessed 12 October 2018).

23. ICT Development Index. ITU (International Telecommunication Union). URL: https://www.itu.int/ net4/ITU-D/idi/2017/ (accessed 12 October 2018).

24. New data visualization on Internet users by region and country, 2010-2016. ITU (International Telecommunication Union). URL: https://www.itu.int/ en/ITU-D/Statistics/Pages/stat/default.aspx (accessed 12 October 2018). 


\section{Information about the Author}

Evgeniy A. Mamay, Candidate of Sciences (Jurisprudence), Associate Professor, Scientific Secretary of the Academic Council, Nizhny Novgorod Academy of the Ministry of Interior of Russia, Ankudinovskoe Highway, 3, 603144 Nizhny Novgorod, Russian Federation, mamai_ea@mail.ru, https:// orcid.org/0000-0002-9386-2747

\section{Информация об авторе}

Евгений Алексеевич Мамай, кандидат юридических наук, доцент, ученый секретарь ученого совета, Нижегородская академия МВД России, Анкудиновское шоссе, 3, 603144 г. Нижний Новгород, Российская Федерация, mamai_ea@mail.ru, https://orcid.org/0000-0002-9386-2747 